Transcontinentales

continentales

Sociétés, idéologies, système mondial

$6 \mid 2008$

Mémoires et nations

\title{
Asie méridionale
}

\section{(2) OpenEdition \\ 1 Journals}

Édition électronique

URL : http://journals.openedition.org/transcontinentales/933

DOI : 10.4000/transcontinentales.933

ISBN : 978-2-7351-1561-7

ISSN : $1775-397 X$

Éditeur

Editions de la maison des sciences de l'homme

Édition imprimée

Date de publication : 30 juin 2008

Pagination : 161

ISBN : 978-2-200-92511-6

ISSN : $1950-1684$

\section{Référence électronique}

«Asie méridionale», Transcontinentales [En ligne], 6 | 2008, document 20, mis en ligne le 06 avril 2011 consulté le 25 septembre 2020. URL : http://journals.openedition.org/transcontinentales/933 ; DOI : https://doi.org/10.4000/transcontinentales.933

Tous droits réservés 
Les ouvrages objets de comptes rendus ne sont pas mentionnés ici.

\section{AFRIQUE}

Mers'e Hazen Wolde Qirqos, Of what I Saw and Heard : the Last Years of Emperor Menelik II \& the Brief Rule of Lyassu, Addis Abeba, Centre français d'études éthiopiennes / Zamra Publishers (Ethiopian Studies $n^{\circ} 1$ ), 2004, $195 \mathrm{p}$.

TORnAY Serge et Estelle SOHIER, Empreintes du temps : les sceaux des dignitaires éthiopiens du règne de Téwodros à la régence de Täfäri Mäkonnen, Addis Abeba, Centre français d'études éthiopiennes / Institute of ethiopian studies/Addis Abeba university (Ethiopian Studies n³), 2007, $261 \mathrm{p}$.

\section{MOYEN-ORIENT}

Chiffoleau Sylvia et Anna Madoeuf (dir.), Les pèlerinages au Maghreb et au MoyenOrient : espaces publics, espaces du public, Beyrouth, Institut français du Proche-Orient, 2005, $406 \mathrm{p}$.

Clauss-Balty Pascale (dir.), Hauran. III, L'habitat dans les campagnes de Syrie du Sud aux époques classique et médiévale. Beyrouth, Institut français du Proche-Orient (Bibliothèque archéologique et historique $\left.\mathrm{n}^{\circ} 181\right), 2008, \mathrm{VIII}-347 \mathrm{p}$.

Dentzer-Feydy Jacqueline, Michèle Vallerin et Thibault Fournet (éd.), Bosra : aux portes de I'Arabie, Beyrouth, Damas, Amman, Institut français du Proche-Orient (Guides archéologiques de I'IFPO n5), 2007, xvI-366 p.

GHAZZAL Zouhair, The Grammars of Adjudication: the Economics of Judicial Decision Making in fin-de-siècle Ottoman Beirut and Damascus, Beyrouth, Institut français du Proche-Orient ( $\left.C P n^{\circ} 21\right), 2007$, xIV-745 p.
Picaudou Nadine (dir.), Territoires palestiniens de mémoire, Paris, Karthala ; Beyrouth, Institut français du Proche-Orient, 2006, $379 \mathrm{p}$.

VAUtHIER Élisabeth, La création romanesque contemporaine en Syrie de 1967 à nos jours, Damas, Institut français du ProcheOrient (PIFD n²233), 2007, $446 \mathrm{p}$.

Vibert-Guigue Claude et Ghazi Bisheh, Les peintures de Qusayr 'Amra : un bain omeyyade dans la bâdiya jordanienne, Beyrouth, Institut français du Proche-Orient (Bibliothèque archéologique et historiquen ${ }^{\circ}$ 179, Jordanian Archaeology $\left.n^{\circ} 1\right), 2007,226 \mathrm{p}$.

\section{ASIE MÉRIDIONALE}

Eberhard Christophe (éd.), Law, Land Use and the Environment: Afro-Indian Dialogues/ Enjeux fonciers et environnementaux: dialogues afro-indiens, Pondichéry, Institut français de Pondichéry (Sciences sociales $\left.n^{\circ} 13\right), 2008, x v-549 p$.

Sebastia Brigitte, Les rondes de saint Antoine: culte, possession et troubles psychiques en Inde du sud, Montreuil, Aux lieux d'être (Sous prétexte de médecines), 2007, 349 p.

\section{AMÉRIQUE LATINE}

Hoffmann Odile et María Teresa Rodriguez (éd.), Los retos de la diferencia: los actores de la multiculturalidad entre México y Colombia, Mexico, Centre d'études mexicaines et centraméricaines / Centro de Investigación y Estudios Superiores en Antropología Social (CIESAS) / Institut de recherche pour le développement ; Bogotá, Instituto Colombiano de Antropología e Historia (ICAH), 2007, 551 p. (Publicaciones de la Casa Chata)

Mc Evor Carmen et Anna María Stuven (dir.), La república peregrina : hombres de armas y letras en América del Sur, 1800-1884, Lima, 


\section{OUVRAGES REÇUS}

Institut français d'études andines / Instituto de Estudios Peruanos (Série Estudios históricos $n^{\circ} 46$, Actes et mémoires de I'IFEA $\left.\mathrm{n}^{\circ} 14\right), 2007,562 \mathrm{p}$.

ReCondo David, La Política del Gatopardo: multiculturalismo y democracia en Oaxaca, Mexico, Centre d'études mexicaines et centraméricaines / Centro de Investigación y Estudios Superiores en Antropología Social (CIESAS), 2007, $486 \mathrm{p}$.

Van Deusen Nancy E., Entre lo sagrado y lo mundano: la práctica institutional y cultural del recogimiento en la Lima virreinal, Lima, Fondo editorial de la Pontifica Universidad Católica del Perú / Institut français d'études andines (Travaux de I'IFEA $\left.\mathrm{n}^{\circ} 241\right), 2007,330 \mathrm{p}$.

\section{EUROPE}

Bauer Paul et Mathilde Darley (éd.), Borders of the European Union :Strategies of Crossing and Resistance/Frontières de I'Union européenne: franchissements et résistances, Prague, Centre français de recherche en sciences sociales (Cahiers du CEFRES), 2007, $294 \mathrm{p}$.

Maurel Marie-Claude et Guillaume LACQUEMENT (dir.), Agriculture et ruralité en Europe centrale, Montreuil, Aux lieux d'être; Prague, Centre français de recherche en sciences sociales, 2007, $164 \mathrm{p}$.

MAURel Marie-Claude et Françoise MAYer, L'Europe et ses représentations du passé : les tourments de la mémoire, Paris, L'Harmattan; Prague, Centre français de recherche en sciences sociales, 2008, $224 \mathrm{p}$. 